\title{
CLIMA ORGANIZACIONAL: MODELO DE PESQUISA DOS FATORES DE SATISFAÇÃO NO TRABALHO E AMBIENTE ORGANIZACIONAL
}

\author{
Laís Novaes Pillar de Oliveira Castro \\ Mestre em Engenharia de Produção - UENF \\ laispillar@hotmail.com
}

Túlio Baita dos Reis

Mestre em Engenharia de Produção - UENF

tuliobaitareis@gmail.com

Everton Luis Pinheiro Dos Santos

Graduando em Administração/ISECENSA/RJ

esantos@dinizcampos.com.br

George Silva Machado

Graduando em Administração/ISECENSA/RJ

gegeklj45@gmail.com

\section{Rosana Candiano Rangel}

Graduando em Administração/ISECENSA/RJ

rosana30candiano@gmail.com

\section{RESUMO}

As organizações são sistemas sociais criadas com a função de suprir alguma necessidade do homem e, para isso, precisam de uma estrutura com pessoas nelas envolvidas. Este projeto teve por objetivo, desenvolver um instrumento de pesquisa de clima organizacional a fim de demonstrar a importância do clima organizacional no que se refere à satisfação dos colaboradores nas organizações. O estudo buscou, por meio da literatura existente, explicar as complexidades das organizações e das pessoas como elemento teórico e entender como elas se manifestam de formas eficazes para a compreensão das dinâmicas de adaptação e integração dos colaboradores. A metodologia deste estudo teve como parâmetros, a ampliação do referencial teórico Clima Organizacional; Desenvolvimento do formulário de pesquisa de Clima Organizacional utilizando escala tipo Likert (satisfação); Aplicação do formulário desenvolvido de clima organizacional; (pesquisa com dados primários); Tabulação dos dados pesquisados; Análise e comparação dos dados; e Análise dos principais resultados que influenciam o desempenho dos colaboradores. Como resultado este estudo validou o modelo de avaliação da satisfação dos funcionários em relação ao clima organizacional de duas empresas, possibilitou uma comparação entre dois setores distintos, o qual permite analisar qual o comportamento da satisfação frente aos critérios que compõem o clima organizacional em ambas empresas pesquisadas.

Palavras-chave: Clima organizacional, satisfação, modelo. 


\title{
CENTRO EDUCACIONAL NOSSA SENHORA AUXILIADORA INSTITUTOS SUPERIORES DE ENSINO DO CENSA CENTRO DE PESQUISA E PÓS-GRADUAÇÃO
}

\begin{abstract}
Organizations are social systems designed in order to supply some of man's necessity, and, for that, they need a structure with people involved in them. This project had the aim to develop a tool of research on organizational environment to show the importance of it referring to the satisfaction of co-workers in these organizations. The study searched, through existent literature, to explain the complexity of organizations and people as theoretical elements and to understand how they express in efficient ways to the understanding of adaptation and integration dynamics among co-workers. This study methodology had as criteria the enlargement of the theoretical reference Organizational Environment; Development of a research form on Organizational Environment using the scale Likert (satisfaction); the developed form application on organizational environment; (research with primary data); Tabulation of surveyed data; Analysis and comparison of data; and Analysis the main results that influence the co-workers' performance. As a result, this study accredited the model of evaluation of employee's satisfaction in relation to the organizational environment of two companies, allowing a comparison between two different sectors that enables to analyze which behavior of satisfaction facing the criteria that make up the organizational environment in both companies surveyed.
\end{abstract}

Keywords: Organizational Climate, Satisfaction and Model.

\section{INTRODUÇÃO}

As organizações são sistemas sociais criadas com a função de suprir alguma necessidade do homem e, para isso, precisam de uma estrutura com pessoas nelas envolvidas. Segundo Lima (2008), o relacionamento interpessoal e o clima dos grupos podem trazer satisfações ou insatisfações pessoais ou grupais, repercutindo na organização/empresa o conjunto de preceitos, políticas da empresa, valores, missão e crenças é que dão forma ao modo personalizado e único de como as pessoas agem e interagem dentro de uma organização e consequentemente colaboram para o estabelecimento de uma cultura organizacional.

Rocha et al. (2013) relata que as atitudes dos funcionários e a capacidade destes de desenvolverem suas atividades em um nível de qualidade compatível com as exigências do mercado estão diretamente relacionadas à competitividade de uma organização. Deste modo, para que ocorra um efetivo desenvolvimento organizacional é necessário que ocorra um aprimoramento técnico a fim de desenvolver a competência pessoal e interpessoal, com intuito de melhorar a qualidade de vida no trabalho resultando em determinado crescimento e desenvolvimento do potencial humano em consequência a produtividade e qualidade nos serviços.

Um clima organizacional favorável propicia a satisfação das necessidades de um colaborador afetando assim positivamente suas atitudes e despertando sua criatividade, seu desejo de inovar, a capacidade de adaptar-se às mudanças no ambiente de trabalho. Em um ambiente globalizado em que as empresas estão inseridas, o fator humano tem sido considerado o grande diferencial das empresas para vencer a competitividade, portanto é cada vez mais necessário conhecer e avaliar o clima existente em suas organizações para uma melhor resolução nas relações interpessoais, reduzindo possíveis conflitos e proporcionando maior satisfação e desempenho dos colaboradores.

Levando-se em conta atualmente os novos conceitos de administração e de gestão participativa, pode-se afirmar que o grande diferencial das organizações corresponde ao seu potencial humano. Deste modo, é essencial investir em atividades que visem à melhoria da qualidade de vida dos seus colaboradores $\mathrm{e}$ atitudes que busquem o aperfeiçoamento do ambiente de trabalho.

Contudo, entendendo a real necessidade de entender o capital humano das organizações como estratégia da melhoria nas rotinas de um sistema organizacional como diferencial competitivo e motivação

Persp. online: hum. \& sociais aplicada., Campos dos Goytacazes, 16 (6), 01-08, 2016 


\section{CENTRO EDUCACIONAL NOSSA SENHORA AUXILIADORA INSTITUTOS SUPERIORES DE ENSINO DO CENSA CENTRO DE PESQUISA E PÓS-GRADUAÇÃO}

dos colaboradores, este projeto tem por objetivo a elaboração de um instrumento de pesquisa que possibilite a empresa analisar o clima organizacional.

Para tanto, esta pesquisa visa promover a validação do modelo proposto por meio da avaliação do clima organizacional e análise das dimensões propostas para este estudo (Desenvolvimento Pessoal, Ambiente Organizacional, Liderança e Equipe, Remuneração e Benefícios, Aspectos Externos). Como objetivos específicos, este buscou-se desenvolver referencial teórico sobre clima organizacional, evidenciar critérios abordados na literatura (1983 a 2015), desenvolver formulário para a avaliar o clima organizacional em pequenas e médias empresas e demonstrar os resultados obtidos na análise das dimensões indicadas pelos autores deste estudo.

\section{METODOLOGIA}

A pesquisa tem natureza descritiva, pois descreve o ambiente pesquisado e compreende aspectos da pesquisa qualitativa/quantitativa e estudo de caso. Utilizou-se a abordagem qualitativa para analisar na literatura aspectos do tema proposto que pudesse embasar a construção do instrumento de pesquisa denominado formulário, utilizado no estudo de caso.

A partir do refinamento dos itens pesquisados foram selecionados/adaptados 21 (vinte e um) critérios para compor as dimensões propostas na pesquisa. O instrumento de pesquisa para avaliação do clima organizacional refere-se a um conjunto de critérios e dimensões relativos ao modo como o colaborador percebe a organização de maneira a aferir o grau de satisfação sobre as atividades que desenvolve que podem ser observados no modelo proposto contido no quadro 1. A partir da concepção do modelo 47 (quarenta e sete) formulários foram aplicados aos colaboradores de duas empresas de médio porte, sendo um comércio e a outra empresa de serviços hospitalares situadas em Campos dos Goytacazes, caracterizando-se também como pesquisa quantitativa. A pesquisa foi aplicada no período de 20 dias nos meses de abril e maio. $\mathrm{O}$ tempo médio de aplicação dos formulários foi de 13 a 16 minutos, podendo variar de acordo com o grau de instrução dos respondentes.

Para a construção do modelo de pesquisa, foi elaborado um refinamento dos principais critérios utilizados pelos seguintes autores, Bispo (2006), Pimenta et al. (2012), Emmendoerfer e Palmeira (2013) e Siqueira e Almeida Neto (2015). O formulário aplicado é composto de 5 dimensões, sendo ao total 21 (vinte e uma) questões fechadas, 1(uma) questão de avaliação em âmbito geral e 1 (um) campo opcional aberto para sugestões, conforme descrito no apêndice 1 (um). Para melhor entendimento das dimensões sugeridas para este estudo, foram propostas as seguintes definições:

- Desenvolvimento Pessoal: avalia possibilidades de crescimento dos colaboradores na organização;

- Ambiente Organizacional: avalia o ambiente interno da organização, estrutura, regras, higiene/segurança e aspectos éticos;

- Liderança e Equipe: avalia a habilidade de influenciar e se comunicar entre líderes e liderados da organização;

- Remuneração e Benefícios: avalia a segurança financeira e estabilidade dos colaboradores na organização;

- Aspectos Externos: avalia o ambiente externo da organização e a forma com que a mesma proporciona o bem estar de seus colaboradores mesmo fora da carga-horária de trabalho. 
Quadro 1: Modelo Proposto

\begin{tabular}{|c|c|c|c|c|c|c|}
\hline \multicolumn{7}{|c|}{ MODELO PROPOSTO } \\
\hline DIMENSÕES & \multicolumn{6}{|c|}{ CRITÉRIOS DE AVALIAÇÃO } \\
\hline $\begin{array}{c}\text { Desenvolvimento } \\
\text { pessoal }\end{array}$ & Satisfação pessoal & $\begin{array}{l}\text { Consideração e } \\
\text { Tolerância }\end{array}$ & $\begin{array}{l}\text { Liberdade e } \\
\text { Autonomia }\end{array}$ & $\begin{array}{l}\text { Incentivos e } \\
\text { reconhecimento }\end{array}$ & Treinamento & \\
\hline $\begin{array}{c}\text { Ambiente } \\
\text { Organizacional }\end{array}$ & $\begin{array}{l}\text { Estrutura e regras } \\
\text { propostos pela } \\
\text { organização }\end{array}$ & $\begin{array}{l}\text { Recursos para } \\
\text { execução do } \\
\text { trabalho }\end{array}$ & Ética & $\begin{array}{c}\text { Existência de } \\
\text { Conflitos internos }\end{array}$ & $\begin{array}{l}\text { Estabilidade no } \\
\text { emprego }\end{array}$ & $\begin{array}{l}\text { Higiene e } \\
\text { Segurança }\end{array}$ \\
\hline Liderança e Equipe & Gestão / Liderança & $\begin{array}{l}\text { Relacionamento } \\
\text { Interpessoal }\end{array}$ & $\begin{array}{l}\text { Suporte para } \\
\text { tomada de decisão }\end{array}$ & Comunicação & & \\
\hline $\begin{array}{c}\text { Remuneração e } \\
\text { Benefícios }\end{array}$ & $\begin{array}{l}\text { Programa de } \\
\text { benefícios }\end{array}$ & Remuneração & & & & \\
\hline Aspectos Externos & $\begin{array}{l}\text { Meios de Transporte } \\
\text { para ir e vir do } \\
\text { trabalho }\end{array}$ & $\begin{array}{l}\text { Imagem da } \\
\text { organização }\end{array}$ & Férias e lazer & Vida Social & & \\
\hline
\end{tabular}

Na a composição do formulário, foi inserida a escala tipo Likert para avaliar os critérios extraídos da literatura e realizar a avaliação global das dimensões propostas. A escala proposta é composta por 5 pontos, a saber: 5 = Muito Satisfeito; $4=$ Satisfeito; $3=$ Neutro; $2=$ Insatisfeito; $1=$ Muito Insatisfeito. $O$ formulário foi aplicado de maneira confidencial. O tratamento dos dados deste foi efetuado de forma global, não sendo sujeito a uma análise individualizada, o que significa que o anonimato do colaborador foi respeitado. Para análise dos dados foi utilizada média aritmética.

\section{RESULTADOS}

Os resultados foram extraídos a partir da análise realizada das respostas dos formulários baseado no modelo proposto. O estudo de caso deste trabalho avaliou dois cenários de mercado, empresa do setor de Comércio Varejista e empresa de Serviços Hospitalares. Os resultados apurados em cada um dos 21 critérios foram agrupados nas dimensões apresentadas neste estudo: Desenvolvimento Pessoal, Ambiente Organizacional, Liderança e Equipe e Aspectos Externos. Destaca-se que a validação do modelo proposto, tem como objetivo identificar o grau de satisfação dos colaborados em relação ao clima organizacional e criar uma comparação entre os diferentes ambientes de trabalho. 


\section{CENTRO EDUCACIONAL NOSSA SENHORA AUXILIADORA \\ INSTITUTOS SUPERIORES DE ENSINO DO CENSA CENTRO DE PESQUISA E PÓS-GRADUAÇÃO}

Empresa do Comércio Varejista

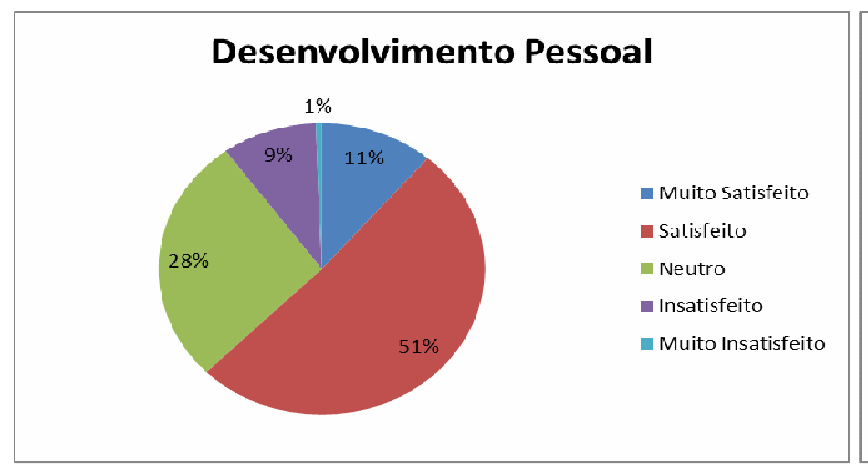

Empresa de Serviços Hospitalares

\section{Desenvolvimento Pessoal}

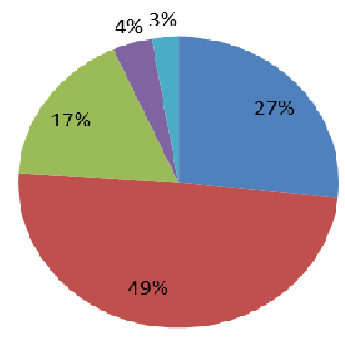

Muito Satisfeito

- Satisfcito

Neutro

- Insatisfeito

Muito Insatisfeito

A primeira dimensão refere-se ao Desenvolvimento Pessoal, avaliada por meio de critérios de satisfação pessoal, consideração e tolerância, liberdade e autonomia, incentivos e reconhecimento e treinamento, que contribuem para uma análise de quando um colaborador se sente saisfeito e a vontade com as tarefas e funções atribuidas. Embora os cenários das empresas sejam diferentes em sua grande maioria os colaboradores demonstran-se satisfeitos em ambos os ambientes pesquisados. Conforme observado nos gráficos $51 \%$ e $49 \%$ dos colaboradores estão satisfeitos com comércio varejista e a empresa de serviços hospitalares, quanto ao desenvolvimento pessoal.

Empresa do Comércio Varejista

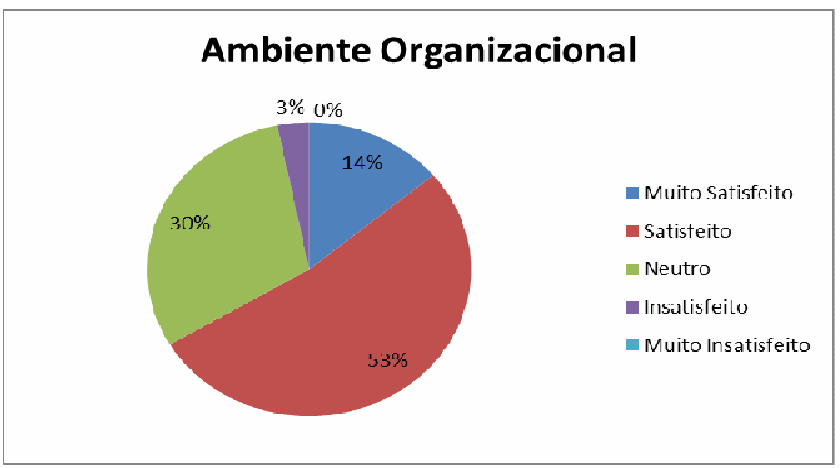

Empresa de Serviços Hospitalares

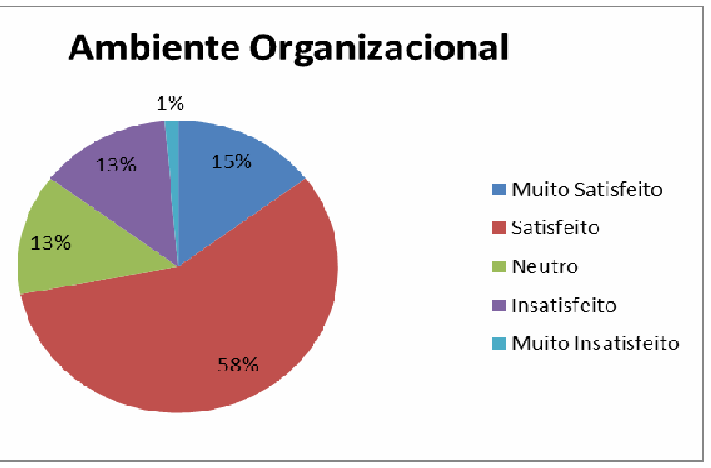

A segundo dimensão refere-se ao Ambiente Organizacional, o qual é de responsabilidade da empresa fornecer as condições necessárias aos colaborados para a realização de suas atribuições que são definidas pelos seguintes critérios: Estrutura e regras propostas pela organização, recursos para execução do trabalho, ética, exisência de conflitos internos, estabilidade no emprego e higiene e segurança. Tais critérios permitem avaliar a satisfação do colaborador quanto ao empenho da empresa em fornecer os melhores recursos. Sabese que para um melhor desempenho da equipe estes fatores são fundamentais para melhores práticas e maior produtividade dos colaboradores. $\mathrm{O}$ que pode ser percebido nas duas empresas pesquisadas é que ambas estão empenhadas em oferecer aos colaboradores os recursos necessários para suas atividades, independente das funções ocupa. No Comérico Varejista 67\% estão muito satisfeitos e satisfeitos, já o cenário de Serviços Hospitalares apresenta o mesmo padrão de satisfação acumulando $73 \%$ entre muito satisifeito e satisfeito. 
Empresa do Comércio Varejista

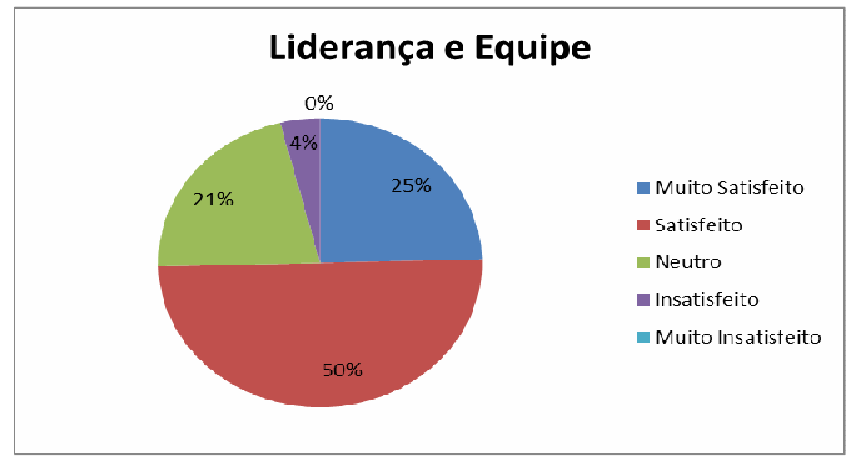

Empresa de Serviços Hospitalares

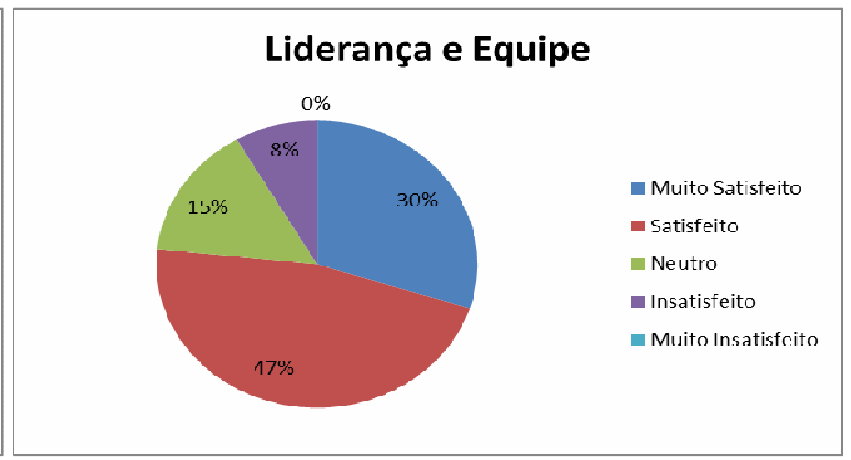

A terceira dimensão refere-se a gestão de pessoas, a qual está diretamente ligada ao desemepenho dos líderes, gerentes ou supervisores dos colaboradores, representado pelos seguintes critérios: Gestão e liderança, relacionamento interpessoal, suporte para tomada de decisão e comunicação. Portanto, esta dimensão avalia a atuação e o relacionamento dos líderes da empresa e seus colaboradores. Em ambos os cenários mais de $70 \%$ dos colaboradores estão muito satisfeitos ou satisfeitos, o que permite afirmar que os gestores de ambas empresas possuem um bom desempenho e relacionamento com a equipe.

Empresa do Comércio Varejista

\section{Empresa de Serviços Hospitalares}

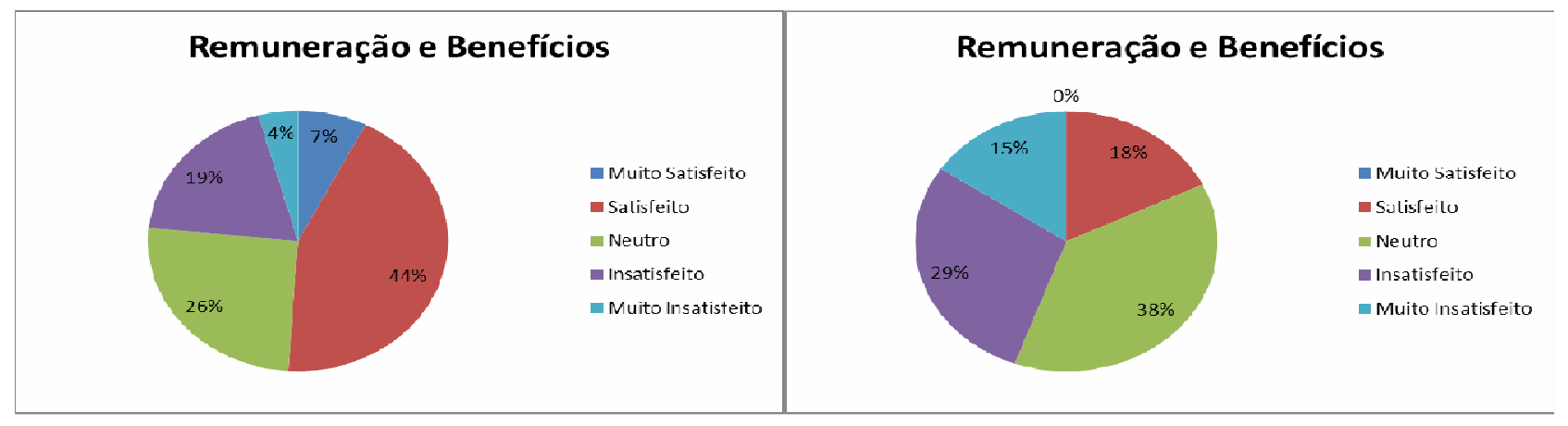

A quarta dimensão avalia a segurança financeira e estabilidade dos colaboradores que são representadas pelos seguintes aos critérios: Programa de benefícios e remuneração. Em um cenário de grande instabilidade provocada pela atual crise econômica e política vivenciada no país, o que se percebe é que os diferentes setores apresentaram resultados distintos. Apesar do comércio vir sofrendo queda no último trimestre, podemos concluir que a empresa pesquisada vem se empenhando em ofercer uma remuneração condizente com a atual realidade do mercado, pois $51 \%$ do colabodores se dizem satisfeitos com esta dimensão. Tal cenário não se apresenta do mesmo modo no setor de Serviços Hospitalares, no qual 38\% se declaram neutro e $44 \%$ do colaboradores estão insatisfeitos ou muito insatisfeitos com a remuneração atual. 


\begin{tabular}{|c|c|c|c|}
\hline Aspectos Externos & & Aspectos Externos & \\
\hline & 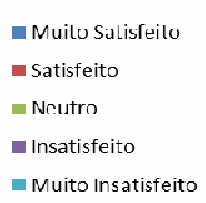 & & $\begin{array}{l}\text { - Muito Satisfeito } \\
\text { - Satisfeito } \\
\text { - Neutro } \\
\text { - Insatisfeito } \\
\text { - Muilu Insalis }\end{array}$ \\
\hline
\end{tabular}

A quinta e última dimensão refere-se aos Aspectos Externos a organização e como a mesma proporciona o bem estar de seus colabores mesmo fora da carga-horária de trabalho. Para compor esta dimensão são avaliados os seguintes critérios: Meios de transporte para ir e vir do trabalho, imagem da organização, férias e lazer e vida social. Um dos fatores que influenciam pode estar relacionado ao fato de ambas as empresas estarem localizadas na região central na cidade, a qual permite uma fácil locomoção de seus colaboradores, o que pode colaborar para o resultado de $55 \%$ de satisfação da empresa de Comércio Varejista e 63\% na empresa de Serviços Hospitalares.

\section{CONSIDERAÇÕES FINAIS}

A pesquisa realizada teve como objetivo principal promover a validação do modelo proposto por meio da avaliação do clima organizacional e análise das dimensões propostas para este estudo (Desenvolvimento Pessoal, Ambiente Organizacional, Liderança e Equipe, Remuneração e Benefícios, Aspectos Externos). Além disso, este estudo buscou desenvolver referencial teórico sobre clima organizacional, evidenciar critérios abordados na literatura, desenvolver formulário para avaliar o clima organizacional em pequenas e médias empresas e demonstrar os resultados obtidos na análise das dimensões indicadas pelos autores deste estudo.

No que diz respeito à validação/avaliação, foram entrevistados 47 (quarenta e sete) colaboradores de duas empresas de segmentos distintos: Comércio Varejista e Serviços Hospitalares. Destaca-se que em ambos os ambientes pesquisados, pode-se constatar grau de satisfação elevado, exceto na análise da dimensão Remuneração e Benefícios, na qual os resultados da satisfação dos colaboradores da empresa de Serviços Hospitalares foram de $18 \%$, quando na empresa de Comércio Varejista percentual deste foi de $44 \%$. Vale destacar que nesta mesma dimensão o número de respostas "neutro" foi acentuado. Isso pode evidenciar que os colaboradores não se sentiram a vontade para avaliar a remuneração e os benefícios oferecidos pela empresa ou não soube opinar.

Contudo, a partir do referencial teórico desenvolvido, seleção dos critérios apresentados pela literatura pesquisada, proposição das dimensões utilizadas neste estudo, aplicação dos formulários e análise de ambas as empresas o modelo proposto foi "experimentado" e validado. Sugere-se que o mesmo seja também aplicado em outras e diferentes organizações para investigação de resultados e ampliação para pesquisas que envolvem também a cultura organizacional. Espera-se que a combinação e apuração dos elementos cultura e clima organizacional possam melhorar ainda mais o desempenho organizacional das empresas. 


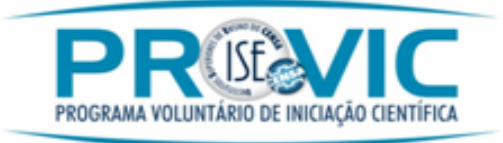

\section{CENTRO EDUCACIONAL NOSSA SENHORA AUXILIADORA \\ INSTITUTOS SUPERIORES DE ENSINO DO CENSA \\ CENTRO DE PESQUISA E PÓS-GRADUAÇÃO}

Esta pesquisa teve como principais limitações, a dificuldade da aplicação dos formulários durante a rotina de trabalho das empresas pesquisadas. Os resultados originados pela pesquisa estão restritos aos ambientes pesquisados. Dessa forma, não é possível garantir que a aplicação da mesma fornecerá resultados iguais ou parecidos em outros ambientes.

\section{REFERENNCIAS}

BISPO, C. A. F. Um novo modelo de pesquisa de clima organizacional. Produção, v. 16, n. 2, p. 258-273, Maio/Ago. 2006.

EMMENDOERFER, M. L.; PALMEIRA, M. L. Funcionário feliz é sinônimo de cliente satisfeito? Um estudo a partir de uma pesquisa de clima organizacional. REDIGE v. 4, n. 03, dez. 2013.

LIMA, S. A. P. Clima e Cultura Organizacional no Ambiente Empresarial. Revista Científica Eletrônica de Administração - ISSN: 1676-6822. Ano VIII - Número 15 - Dezembro de 2008.

PIMENTA, R. C. Q.; AOUAR, W. A. E.; OLIVEIRA, J. A. Clima organizacional em instituto de pesquisa tecnológica. Revista Eletrônica do Mestrado Profissional em Administração da Universidade Potiguar - RAUNP. Ano IV, n. 2 - abr./set. 2012.

ROCHA, L. C. S.; PELOGIO, E. A.; AÑEZ, M. E. M. Cultura e clima organizacionais: um estudo em indústrias de laticínios do Estado do Rio Grande do Norte. Gestão da Produção, São Carlos, v. 20, n. 2, p. $455-468,2013$.

SIQUEIRA, C. F.; NETO, J. L. A. Fatores influenciadores na Cultura e no Clima Organizacional que refletem na motivação, liderança e comunicação de uma empresa de Juazeiro do Norte - CE. Revista de Psicologia. Ano 9, No. 25, Fevereiro/2015. 